\title{
Proposal of Bisgaardia hudsonensis gen. nov., sp. nov. and an additional genomospecies, isolated from seals, as new members of the family Pasteurellaceae
}

Correspondence
G. Foster
Geoffrey.Foster@sac.co.uk

\author{
G. Foster, ${ }^{1}$ R. Higgins, ${ }^{2}$ D. Leclair, ${ }^{3}$ B. M. Korczak, ${ }^{4}$ I. Mikaelian, ${ }^{2}$ \\ I. A. P. Patterson ${ }^{1} \dagger$ and P. Kuhnert ${ }^{4}$ \\ ${ }^{1}$ SAC Consulting Veterinary Services, Inverness, UK \\ ${ }^{2}$ College of Veterinary Medicine, University of Montreal, Canada \\ ${ }^{3}$ Nunavik Research Centre, Makivik Corporation, Kuujjuaq, Canada \\ ${ }^{4}$ Institute of Veterinary Bacteriology, University of Bern, Switzerland
}

The family Pasteurellaceae accommodates a broad group of Gram-negative, chemo-organotrophic, facultatively anaerobic and fermentative bacteria and currently contains 15 recognized genera and more than 60 species with validly published names (Christensen \& Bisgaard, 2008; Kuhnert et al., 2010). Members of the family Pasteurellaceae are generally inhabitants of the mucous membranes of man and animals. Many species of the family are known to be associated with and/or cause disease in many mammalian

tPresent address: Veterinary Sciences Division, Agri-Food and Biosciences Institute, Belfast, Northern Ireland.

The GenBank/EMBL/DDBJ accession numbers for the 16S rRNA gene sequences determined for nine strains in this study are GU295083-GU295091. The GenBank accession number for the $16 S$ rRNA gene sequence of strain M327/99/2 ${ }^{\top}$ is GU295084. Partial $r p o B$ and infB gene sequences for nine strains have been deposited under the numbers GU295092-GU295100 and GU295101GU295109, respectively. The partial recN gene sequences of ten strains have been deposited with accession numbers GU295074-GU295082 and GU321105.

Supplementary figures are available with the online version of this paper. species as well as in birds and tortoises (Bisgaard, 1993; Frederiksen, 1993). The range of hosts for these organisms has been extended with the publication of three novel species from marine mammals, namely Actinobacillus delphinicola (Foster et al., 1996) from several species of cetacean, Actinobacillus scotiae (Foster et al., 1998) from porpoises and Phocoenobacter uteri (Foster et al., 2000) also from porpoises. Reports of the isolation of members of the family Pasteurellaceae from seals however are limited and in the examples that do exist, there is little information given regarding the methods used for their identification (Baker \& Ross, 1992). In this paper, we report the results of an investigation using a polyphasic taxonomic approach of novel members of the family Pasteurellaceae recovered from seals in Canada and Scotland. A new genus, novel species and new genomospecies are described.

Investigations into the deaths of 21 ringed seals (Phoca hispida) near the communities of Umiujaq $\left(56^{\circ} 33^{\prime} \mathrm{N}\right.$ $76^{\circ} 33^{\prime} \mathrm{W}$ ) and Sanikiluaq ( $\left.56^{\circ} 36^{\prime} \mathrm{N} 79^{\circ} 12^{\prime} \mathrm{W}\right)$, Eastern Hudson Bay, Northern Quebec, Canada, in the autumn of 1998, lead to the recovery of three strains (M327/99/1, 
M327/99/2 ${ }^{\mathrm{T}}$ and M327/99/3) of an unknown Gramnegative, rod-shaped bacterium. The strains were isolated from the lungs of three out of four of the animals necropsied and were found to be phenotypically similar to members of the family Pasteurellaceae. One of these strains, M327/99/2 ${ }^{\mathrm{T}}\left(=98-\mathrm{D}-690 \mathrm{~B}^{\mathrm{T}}\right)$, was sequenced and deposited in GenBank (GenBank accession no. AJ251339). Following the seal mortalities, two disease surveys took place in Hudson Bay and Ungava Bay in winter 1999 to determine the health status of ringed seals. Additional material was collected for bacteriological analysis as part of these studies. A further two similar isolates (M327/99/4 and M327/99/5) were cultured from the retro-mandibular lymph nodes of two adult seals harvested in Aupaluk $\left(59^{\circ} 45^{\prime} \mathrm{N}\right.$ $69^{\circ} 41^{\prime} \mathrm{W}$ ) and from a lymph node and tonsil of a young adult seal killed near the community of Kuujjuaq $\left(58^{\circ} 06^{\prime} \mathrm{N} 68^{\circ} 24^{\prime} \mathrm{W}\right)$. Lungs and lymph nodes of the seals did not show any macroscopic or microscopic lesions that could have been associated with the bacterium.

In Scotland, seals reported as part of the Marine Mammal Strandings Scheme were necropsied as part of an investigation into the causes of death in marine mammals. Examinations were carried out in accordance with a nationally agreed protocol (Kuiken \& Hartmann, 1991) and selected tissues were collected for bacteriological culture. Three strains that were similar in appearance to the isolates from ringed seals were recovered from two grey seals (Halichoerus grypus) in 1996 and 1997 and a harbour seal (Phoca vitulina) in 1998. Strain M1765/96/5 was recovered from the liver, lung and pre-scapular lymph node of a grey seal which was suspected to have died from septicaemia and from which Arcanobacterium phocae was also cultured. Strain M1718/97/2 was recovered from the lung and kidney of a further grey seal which appeared to be in good condition but had been shot and M2461/98/1 was recorded from only the lung of a harbour seal pup alongside Arcanobacterium phocae. The latter animal, weighing $14.5 \mathrm{~kg}$ had been losing body condition and had a midsternal blubber thickness of $9 \mathrm{~mm}$. It had not been feeding and was ill with a significant parasitic pneumonia. Associated with this was haemorrhage from the lungs into the airways.

Primary isolations were made on Columbia agar (Oxoid) supplemented with $5 \%$ defibrinated sheep blood (CSBA) that was incubated at $37^{\circ} \mathrm{C}$ in an aerobic atmosphere containing $10 \% \mathrm{CO}_{2}$. Isolates were subcultured to CSBA to provide inocula for biochemical tests. Catalase, oxidase, $\mathrm{X}$ and $\mathrm{V}$ factor requirement, indole, nitrate reduction, VogesProskauer, arginine dihydrolase, ornithine decarboxylase, lysine decarboxylase, urease, acid production from carbohydrates and ability to grow in different atmospheres, at selected temperatures, without blood or serum and on MacConkey agar were determined as described previously (Foster et al., 1996, 1998). The biochemical characteristics of the strains were also examined with the API ZYM system (bioMérieux) according to the manufacturer's instructions. Reactions were scored as $0,1,2,3,4$ or 5 on the basis of the results of a comparison with the colour chart of the manufacturer; scores of 3,4 or 5 were considered strong positive reactions and scores of 1 or 2 were considered weak positive reactions. The $\mathrm{G}+\mathrm{C}$ content of DNA was determined as described by Garvie (1978).

Colonies of the isolates grown on CSBA were circular, entire, low convex, grey, translucent or opaque, nonhaemolytic and $0.5 \mathrm{~mm}$ in diameter after $24 \mathrm{~h}$ of aerobic incubation at $37{ }^{\circ} \mathrm{C}$. Elevated levels of $\mathrm{CO}_{2}$ were not required for subculture. The cells were Gram-negativestaining and rod-shaped. The organisms were catalasepositive, oxidase-positive and non-motile. They grew under anaerobic conditions on pre-reduced CSBA plates using the Oxoid Anaerogen system and on Columbia agar without blood or serum added. Growth did not occur on MacConkey agar with or without $\mathrm{NaCl}$. They grew at $22{ }^{\circ} \mathrm{C}$, but not at $42{ }^{\circ} \mathrm{C}$. Nitrate was reduced to nitrite. The organisms were negative for the Voges-Proskauer reaction and in tests for urease, indole, arginine dihydrolase, lysine decarboxylase and ornithine decarboxylase. Acid was produced from D-glucose and other carbohydrates listed with the description of the species. Using the API ZYM system, strong positive reactions were observed for alkaline phosphatase, leucine arylamidase, acid phosphatase and $\alpha$ fucosidase and a weak positive reaction was obtained for naphthol-AS-BI-phosphohydrolase.

The eight isolates could not be separated phenotypically and were suspected of belonging to the same species within the family Pasteurellaceae. This was also the case when testing the eight isolates on the Vitek 2 system (bioMérieux) using GN and NH cards and resulting in identical profiles with each panel. Positive reactions were obtained for arginine arylamidase, leucine arylamidase, phenylalanine arylamidase, phosphorylcholine, D-galactose, D-mannose, phosphatase and phenylphosphonate. Negative reactions were obtained for acid production from D-mannitol, sorbitol, sucrose and trehalose, while variable reactions were observed with D-glucose and maltose. Differences in acid production from some sugars observed between the commercial Vitek 2 system and the conventional tube assay have previously been seen and may be due to the fact that the Vitek 2 tests use large inocula and short incubation times, thereby not necessarily measuring fermentation but rather acidification of sugars (Kuhnert et al., 2010). All other results obtained with the Vitek 2 system are provided in the species description. All of the strains were subjected to molecular characterization to determine their taxonomic status.

Phylogenetic analysis was performed for four different genes with all eight isolates. Sequences for partial $16 \mathrm{~S}$ rRNA, $r p o B$, infB and $r e c N$ genes were determined as described previously (Kuhnert et al., 2002; Korczak et al., 2004; Kuhnert \& Korczak, 2006; Mayor et al., 2006). The $\inf B$ and $\operatorname{recN}$ gene sequences for the recently described genus Chelonobacter as well as the partial $r e c N$ gene sequence of the related species [Pasteurella] testudinis were also determined in the framework of this study. For the partial recN gene sequence of Chelonobacter oris $1662^{\mathrm{T}}$, 
primers recN_Ptes-2 (5'-CGGTCAATATCGAAGCGATGC-3') and recN_Chel-3 (5'-GTTGCTTCCTGTACTTGAATC-3') were used in combination with recN-L and recN-R, respectively (Kuhnert \& Korczak, 2006). The GenBank accession numbers for the gene sequences are given in the individual phylogenetic trees for each gene as presented in Supplementary Figs S1-S4 (available in IJSEM Online).

A combined tree of all four genes is given in Fig. 1. The eight strains formed a monophyletic, genus-like cluster within the family Pasteurellaceae, for which the new genus name Bisgaardia gen. nov. is proposed. The Bisgaardia gen. nov. cluster formed two distinct but homogeneous species-like branches. One branch comprised the five isolates from ringed seals (M327/99/1, M327/99/2 ${ }^{\mathrm{T}}$, M327/99/3, M327/99/4, M327/99/5) and the other included the three isolates from the grey and harbour seal (M2461/98/1, M1765/96/5, M1718/97/2). The names Bisgaardia hudsonensis gen. nov., sp. nov. and Bisgaardia genomospecies 1 are proposed for these two lineages. The new genus clustered in the combined tree closest to Histophilus somni $8025^{\mathrm{T}}$. This clearly separated cluster with two branches was reflected in each individual tree (see Supplementary Figs S1-S4). In the 16S rRNA gene tree, the genus Bisgaardia gen. nov. formed a monophyletic branch unrelated to other groups (Supplementary Fig. S1). The $16 \mathrm{~S}$ rRNA gene divergence of the genus Bisgaardia gen. nov. with other members of the family was at least $4 \%$ with 'Actinobacillus porcitonsillarum' showing highest absolute sequence similarity $(95.5 \%)$. The two species of the genus Bisgaardia gen. nov. shared $16 \mathrm{~S}$ rRNA gene sequence similarity of $98.5 \%$. In the $r p o B$ gene-based phylogenetic tree, the genus Bisgaardia gen. nov. clustered in the proximity of the genus Pasteurella (Supplementary Fig. S2). Highest sequence similarity was observed with Pasteurella canis CCUG $12400^{\mathrm{T}}(86.5 \%)$ whereas the two species of the genus Bisgaardia gen. nov. shared $88.5 \%$ similarity within the partial $r p o B$ gene. A similar observation was made in the infB gene-based analysis (Supplementary Fig. S3) where members of Bisgaardia gen. nov. also clustered closest to the genus Pasteurella, whereby Bisgaardia shared on average $81.5 \%$ sequence similarity with Pasteurella canis CCUG $12400^{\mathrm{T}}$. The infB gene sequence similarity between the two novel species of the genus Bisgaardia was $86.5 \%$. Finally, in the $r e c N$ gene-based phylogenetic tree (Supplementary Fig. S4), the closest genus was Histophilus sharing about $72 \%$ sequence similarity. The absolute sequence similarity of this partial gene between the species of the genus Bisgaardia gen. nov. was $88.5 \%$.

Recently it was shown that $r e c N$ gene sequence similarity is suitable for the deduction of genome similarities within the family Pasteurellaceae and can be used as an alternative to DNA-DNA hybridization (Kuhnert \& Korczak, 2006). This approach has since contributed successfully to resolving the taxonomy of the family Pasteurellaceae (Kuhnert et al., 2007; Bisgaard et al., 2007, 2009; Kuhnert et al., 2010). The genetic similarity of Bisgaardia hudsonensis sp. nov. was calculated with all the type species of the 15 genera of the family Pasteurellaceae as well as with Bisgaardia genomospecies 1 (Table 1). The highest genetic relatedness was seen with Histophilus somni $8025^{\mathrm{T}}$, whereas the lowest genetic relatedness was observed with Chelonobacter oris $1662^{\mathrm{T}}$. This was also reflected in the combined tree (Fig. 1) as well as the $r e c N$ gene-based phylogenetic tree (Supplementary Fig. S4). The $16 \mathrm{~S}$ rRNA gene sequence similarity of $>98 \%$ between the two novel Bisgaardia species did not allow clear species separation (Stackebrandt \& Ebers, 2006). However, the recN gene-based similarity of 0.69 was clearly below the threshold of 0.85 normally observed for species of the family Pasteurellaceae and the MLSA phylogeny, as well as the tree topology of the individual trees (Supplementary Figs S1-S4), allowed the distinction of the two homogeneous species within the genus Bisgaardia gen. nov. On the other hand, the genetic similarity value was clearly above the threshold of 0.4 that allows species to be grouped within the same genus.

Therefore, based on phenotypic, phylogenetic and genetic analyses, we propose the new genus Bisgaardia gen. nov. with two species. Given the lack of phenotypic characteristics to separate the two species, we propose Bisgaardia hudsonensis gen. nov., sp. nov. and Bisgaardia genomospecies 1 . The inability to distinguish between the two species using phenotypic tests presents difficulties for diagnostic laboratories encountering isolates of the genus Bisgaardia that are unable to perform sequencing. Differences with respect to host species was the only criterion observed between the strains of the two species examined in this study and additional investigations are necessary to examine further isolates from ringed and common seals as well as isolates from different geographical populations to determine whether host association is a useful indicator for the species of Bisgaardia gen. nov.

The newly characterized genus can be readily distinguished from currently described members of the genera Pasteurella, Haemophilus, Actinobacillus, Mannheimia, Phocoenobacter, Bibersteinia, Lonepinella, Histophilus, Nicoletella, Gallibacterium, Avibacterium, Volucribacter, Aggregatibacter, Chelonobacter and Basfia by the characteristics shown in Table 2 .

\section{Description of Bisgaardia gen. nov.}

Bisgaardia (Bis.ga.ar'di.a. N.L. fem. n. Bisgaardia to honour Magne Bisgaard, a contemporary Danish microbiologist, for his contributions to the taxonomy of the family Pasteurellaceae).

Cells consist of pleomorphic, Gram-negative-staining rods. Non-motile and facultatively anaerobic. Neither X nor $\mathrm{V}$ factors are required for growth. Does not grow on MacConkey agar. Catalase-positive and oxidase-positive. Voges-Proskauer reaction and tests for arginine dihydrolase, ornithine decarboxylase, lysine decarboxylase, urease and indole are negative. Nitrate is reduced to nitrite. Acid is produced from D-glucose, D-galactose, D-mannitol, Dmannose, D-sorbitol, sucrose and trehalose, but not from 




Fig. 1. Combined tree based on $16 \mathrm{~S}$ rRNA, rpoB, infB and $r e c N$ gene sequences. Escherichia coli was included as an outgroup to root the tree. The distance matrix was calculated using Jukes-Cantor correction and the tree was built using neighbour-joining in Bionumerics v.5.1. Cophenic correlations are given, indicating the reliability of the branching compared with the actual genetic relatedness of the taxa. The accession numbers of the gene sequences used for tree construction are listed in the individual trees (see Supplementary Figs S1-S4 in IJSEM Online). Bar, $4 \%$ sequence divergence. 
Table 1. Genetic similarity of Bisgaardia hudsonensis gen. nov., sp. nov. to the type species of genera of the family Pasteurellaceae calculated based on recN gene sequences

\begin{tabular}{|c|c|}
\hline Strain & $\begin{array}{c}\text { Bisgaardia } \\
\text { hudsonensis } \\
\text { M327/99/2 }\end{array}$ \\
\hline Bisgaardia genomospecies $1 \mathrm{M} 1765 / 96 / 5$ & 0.69 \\
\hline Actinobacillus ligneresii NCTC $4189^{\mathrm{T}}$ & 0.04 \\
\hline $\begin{array}{l}\text { Pasteurella multocida subsp. multocida } \\
\text { CCUG } 17976^{\mathrm{T}}\end{array}$ & 0.22 \\
\hline Haemophilus influenzae Rd KW20 & 0.26 \\
\hline Mannheimia haemolytica NCTC $9380^{\mathrm{T}}$ & 0.10 \\
\hline Lonepinella koalarum ATCC $700131^{\mathrm{T}}$ & 0.24 \\
\hline Phocoenobacter uteri NCTC $12872^{\mathrm{T}}$ & 0.11 \\
\hline Gallibacterium anatis CCUG $15563^{\mathrm{T}}$ & 0.01 \\
\hline Volucribacter psittacicida JEO101 & 0.20 \\
\hline Histophilus somni $8025^{\mathrm{T}}$ & 0.32 \\
\hline Avibacterium gallinarum NCTC $11188^{\mathrm{T}}$ & 0.22 \\
\hline Nicoletella semolina CCUG $43639^{\mathrm{T}}$ & 0.05 \\
\hline Bibersteinia trehalosi NCTC $10370^{\mathrm{T}}$ & 0.08 \\
\hline $\begin{array}{l}\text { Aggregatibacter actinomycetemcomitans } \\
\text { HK1651 }\end{array}$ & 0.19 \\
\hline Chelonobacter oris $1662^{\mathrm{T}}$ & 0.00 \\
\hline Basfia succiniciproducens DSM $22022^{\mathrm{T}}$ & 0.21 \\
\hline
\end{tabular}

D-xylose. Alkaline phosphatase and $\alpha$-fucosidase are produced in large amounts, but $\alpha$-glucosidase is not produced. The $\mathrm{G}+\mathrm{C}$ content of the DNA is $39.5 \mathrm{~mol} \%$. Isolated from lungs and other tissues of seals. Phenotypic tests that separate the genus Bisgaardia from the other members of the family Pasteurellaceae are given in Table 2. The type species is Bisgaardia hudsonensis.

\section{Description of Bisgaardia hudsonensis sp. nov.}

Bisgaardia hudsonensis (hud.so.nen'sis. N.L. fem. adj. hudsonensis from Hudson Bay, the area of Canada where the strains originated).

Colonies on CSBA are circular, entire, low convex, smooth, grey and attain a diameter of $0.5 \mathrm{~mm}$ after $48 \mathrm{~h}$ of aerobic incubation at $37{ }^{\circ} \mathrm{C}$. Non-haemolytic. Growth occurs on media without blood or serum. Growth occurs at $22{ }^{\circ} \mathrm{C}$, but not at $42{ }^{\circ} \mathrm{C}$. In addition to characteristics for the genus, acid is produced from myo-inositol and maltose, but not from adonitol, dulcitol, lactose, melibiose, raffinose or Lrhamnose. Leucine arylamidase and acid phosphatase are produced in large amounts and naphthol-AS-BI-phosphohydrolase is produced in lesser amounts. Valine arylamidase, cystine arylamidase, trypsin, chymotrypsin, phosphoamidase, $\alpha$-galactosidase, $\beta$-galactosidase, $\beta$-glucosidase,

Table 2. Key characteristics for differentiation of Bisgaardia gen. nov. from other genera of the family Pasteurellaceae

Genera: 1, Actinobacillus sensu stricto (data from Christensen \& Bisgaard, 2004); 2, Pasteurella sensu stricto (Mutters et al., 1985); 3, Haemophilus sensu stricto (includes $H$. influenzae, $H$. haemolyticus and $H$. aegypticus - results for $H$. parainfluenzae and $H$. pittmaniae are given in square brackets) (Nørskov-Lauritsen et al., 2005); 4, Mannheimia (Angen et al., 1999); 5, Lonepinella (Osawa et al., 1995); 6, Phocoenobacter (Foster et al., 2000); 7, Gallibacterium (Christensen et al., 2003; Bisgaard et al., 2009); 8, Volucribacter (Christensen et al., 2004); 9, Histophilus (Angen et al., 2003); 10, Avibacterium (Blackall et al., 2005); 11, Nicoletella (Kuhnert et al., 2004); 12, Bibersteinia (Blackall et al., 2007); 13, Aggregatibacter (Patel et al., 2004; Nørskov-Lauritsen \& Kilian, 2006); 14, Chelonobacter (Gregersen et al., 2009); 15, Basfia (Kuhnert et al., 2010); 16, Bisgaardia gen. nov. (this study). +, Positive; -, negative; v, variable; w, weak positive; ND, no data available.

\begin{tabular}{|c|c|c|c|c|c|c|c|c|c|c|c|c|c|c|c|c|}
\hline Characteristic & 1 & 2 & 3 & 4 & 5 & 6 & 7 & 8 & 9 & 10 & 11 & 12 & 13 & 14 & 15 & 16 \\
\hline Haemolysis & V & - & $\mathrm{v}$ & $\mathrm{v}$ & - & - & + & - & $\mathrm{v}$ & - & - & + & v & + & - & - \\
\hline Catalase & $\mathrm{V}$ & + & $\mathrm{V}$ & $\mathrm{v}$ & - & - & + & $\mathrm{V}$ & - & $\mathrm{V}$ & + & $\mathrm{V}$ & $\mathrm{v}$ & + & - & + \\
\hline Urease & + & $-{ }^{\star}$ & $+[\mathrm{v}]$ & - & - & - & - & - & - & - & + & - & - & - & - & - \\
\hline Oxidase & + & + & + & + & - & + & + & $\mathrm{V}$ & + & + & + & $\mathrm{V}$ & - & + & + & + \\
\hline Indole & - & + & $\mathrm{v}$ & - & - & - & - & - & + & - & - & - & - & - & - & - \\
\hline D-Galactose & $\mathrm{V}$ & + & + & + & $\mathrm{ND}$ & $\mathrm{ND}$ & + & + & $\mathrm{ND}$ & $\mathrm{V}$ & - & - & $\mathrm{v}$ & $\mathrm{ND}$ & + & + \\
\hline D-Mannitol & $+\dagger$ & $\mathrm{v}$ & - & + & - & - & + & - & $\mathrm{ND}$ & $\mathrm{V}$ & - & + & $\mathrm{V}$ & + & + & + \\
\hline D-Mannose & $\mathrm{V}$ & + & $-[+]$ & - & + & - & + & + & $\mathrm{ND}$ & + & - & + & $\mathrm{v}$ & + & + & + \\
\hline D-Sorbitol & $\mathrm{V}$ & $\mathrm{v}$ & - & $\mathrm{V}$ & - & - & $\mathrm{V}$ & - & $\mathrm{V}$ & $\mathrm{V}$ & - & + & - & - & + & + \\
\hline Sucrose & + & + & $-[\mathrm{v}]$ & + & $\mathrm{v}$ & - & + & + & - & + & - & + & $\mathrm{v}$ & + & + & + \\
\hline Trehalose & $\mathrm{V}$ & $\mathrm{V}$ & - & - & - & - & $\mathrm{V}$ & - & - & $\mathrm{V}$ & - & + & $\mathrm{v}$ & + & + & + \\
\hline D-Xylose & $+\ddagger$ & $-\S$ & V & + & $\mathrm{ND}$ & - & + & - & - & - & - & - & $\mathrm{v}$ & + & + & - \\
\hline$\alpha$-Fucosidase & - & - & - & $\mathrm{V}$ & - & $\mathrm{ND}$ & - & - & $\mathrm{ND}$ & - & $\mathrm{ND}$ & - & $\mathrm{ND}$ & - & $\mathrm{ND}$ & + \\
\hline$\alpha$-Glucosidase & $\mathrm{V}$ & + & - & - & - & $\mathrm{ND}$ & + & - & ND & + & $\mathrm{ND}$ & $\mathrm{v}$ & $\mathrm{V}$ & - & - & - \\
\hline
\end{tabular}

${ }^{*}$ Pasteurella dagmatis positive.

$\dagger$ Actinobacillus suis negative.

$\ddagger$ Actinobacillus ureae negative.

§asteurella multocida variable. 
$\beta$-glucuronidase, $\beta$-glucosaminidase, $\alpha$-mannosidase, esterase (C4), esterase lipase (C8) and lipase (C14) are not produced. Using the Vitek 2 system, positive reactions are obtained for arginine arylamidase, leucine arylamidase, phenylalanine arylamidase, phosphorylcholine, D-galactose, D-mannose, phosphatase and phenylphosphonate. Negative reactions using Vitek 2 are obtained for adonitol, L-arabitol, Ala-Phe-Pro-arylamidase, maltotriose, $\beta$-galactopyranosidase, $\beta$-galactosidase, D-malate, L-pyrrolydonyl arylamidase, $\beta$ - $N$-acetylglucosaminidase, $\gamma$-glutamyltransferase, glutamylarylamidase, $\beta$-glucosidase, $\beta$-xylosidase, $\beta$-alanine arylamidase, L-proline arylamidase, lipase, palatinose, citrate, L-malate, urease, $\mathrm{H}_{2} \mathrm{~S}$, D-tagatose, malonate, L-lactate alkalinization, succinate alkalinization, $\beta$ - $N$-acetylgalactosaminidase, glycine arylamidase, lysine decarboxylase, ornithine decarboxylase, L-histidine, $\beta$-glucuronidase, GluGly-Arg-arylamidase, pyruvate, L-glutamine, cellobiose, 5 -keto-D-gluconate, $\alpha$-galactosidase and coumarate. Variable reactions were observed with $\alpha$-arabinosidase, $N$ acetyl-D-glucosamine, D-ribose, tyrosine arylamidase, starch (glycogen), L-lysine arylamidase and Ellman's reagent.

The type strain is M327/99/2 ${ }^{\mathrm{T}}$ (=CCUG $43067^{\mathrm{T}}=\mathrm{NCTC}$ $\left.13475^{\mathrm{T}}=98-\mathrm{D}-690 \mathrm{~B}^{\mathrm{T}}\right)$. Isolated from ringed seals. Pathological significance is unknown.

\section{Acknowledgements}

The Scottish Strandings Scheme is operated under contract to the UK Department of Environment, Food and Rural Affairs (DEFRA), with financial support from the Scottish Government Marine Directorate.

\section{References}

Angen, Ø., Mutters, R., Caugant, D. A., Olsen, J. E. \& Bisgaard, M. (1999). Taxonomic relationships of the [Pasteurella] haemolytica complex as evaluated by DNA-DNA hybridizations and $16 \mathrm{~S}$ rRNA sequencing with proposal of Mannheimia haemolytica gen. nov., comb. nov., Mannheimia granulomatis comb. nov., Mannheimia glucosida sp. nov., Mannheimia ruminalis sp. nov. and Mannheimia varigena sp. nov. Int J Syst Bacteriol 49, 67-86.

Angen, Ø., Ahrens, P., Kuhnert, P., Christensen, H. \& Mutters, R. (2003). Proposal of Histophilus somni gen. nov., sp. nov. for the three species incertae sedis 'Haemophilus somnus', 'Haemophilus agni' and 'Histophilus ovis'. Int J Syst Evol Microbiol 53, 1449-1456.

Baker, J. R. \& Ross, H. M. (1992). The role of bacteria in phocine distemper. Sci Total Environ 115, 9-14.

Bisgaard, M. (1993). Ecology and significance of Pasteurellaceae in animals. Zentralbl Bakteriol 279, 7-26.

Bisgaard, M., Christensen, J. P., Bojesen, A. M. \& Christensen, H. (2007). Avibacterium endocarditidis sp. nov., isolated from valvular endocarditis in chickens. Int J Syst Evol Microbiol 57, 1729-1734.

Bisgaard, M., Korczak, B. M., Busse, H. J., Kuhnert, P., Bojesen, A. M. \& Christensen, H. (2009). Classification of the taxon 2 and taxon 3 complex of Bisgaard within Gallibacterium and description of Gallibacterium melopsittaci sp. nov., Gallibacterium trehalosifermentans sp. nov. and Gallibacterium salpingitidis sp. nov. Int J Syst Evol Microbiol 59, 735-744.

Blackall, P. J., Christensen, H., Beckenham, T., Blackall, L. L. \& Bisgaard, M. (2005). Reclassification of Pasteurella gallinarum,
[Haemophilus] paragallinarum, Pasteurella avium and Pasteurella volantium as Avibacterium gallinarum gen. nov., comb. nov., Avibacterium paragallinarum comb. nov., Avibacterium avium comb. nov. and Avibacterium volantium comb. nov. Int J Syst Evol Microbiol 55, 353-362.

Blackall, P. J., Bojesen, A. M., Christensen, H. \& Bisgaard, M. (2007). Reclassification of [Pasteurella] trehalosi as Bibersteinia trehalosi gen. nov., comb. nov. Int J Syst Evol Microbiol 57, 666-674.

Christensen, H. \& Bisgaard, M. (2004). Revised definition of Actinobacillus sensu stricto isolated from animals. A review with special emphasis on diagnosis. Vet Microbiol 99, 13-30.

Christensen, H. \& Bisgaard, M. (2008). Taxonomy and biodiversity of members of Pasteurellaceae. In Pasteurellaceae: Biology, Genomics and Molecular Aspects, pp. 1-26. Edited by P. Kuhnert \& H. Christensen. Norwich, UK: Caister Academic Press.

Christensen, H., Bisgaard, M., Bojesen, A. M., Mutters, R. \& Olsen, J. E. (2003). Genetic relationships among avian isolates classified as Pasteurella haemolytica, 'Actinobacillus salpingitidis' or Pasteurella anatis with proposal of Gallibacterium anatis gen. nov., comb. nov. and description of additional genomospecies within Gallibacterium gen. nov. Int J Syst Evol Microbiol 53, 275-287.

Christensen, H., Bisgaard, M., Aalbaek, B. \& Olsen, J. E. (2004). Reclassification of Bisgaard taxon 33, with proposal of Volucribacter psittacicida gen. nov., sp. nov. and Volucribacter amazonae sp. nov. as new members of the Pasteurellaceae. Int J Syst Evol Microbiol 54, 813818.

Foster, G., Ross, H. M., Malnick, H., Willems, A., Garcia, P., Reid, R. J. \& Collins, M. D. (1996). Actinobacillus delphinicola sp. nov., a new member of the family Pasteurellaceae Pohl (1979) 1981 isolated from sea mammals. Int J Syst Bacteriol 46, 648-652.

Foster, G., Ross, H. M., Patterson, I. A. P., Hutson, R. A. \& Collins, M. D. (1998). Actinobacillus scotiae sp. nov., a new member of the family Pasteurellaceae Pohl (1979) 1981 isolated from porpoises (Phocoena phocoena). Int J Syst Bacteriol 48, 929-933.

Foster, G., Ross, H. M., Malnick, H., Willems, A., Hutson, R. A., Reid, R. J. \& Collins, M. D. (2000). Phocoenobacter uteri gen. nov., sp. nov., a new member of the family Pasteurellaceae Pohl (1979) 1981 isolated from a harbour porpoise (Phocoena phocoena). Int J Syst Evol Microbiol 50, 135-139.

Frederiksen, W. (1993). Ecology and significance of Pasteurellaceae in man - an update. Zentralbl Bakteriol 279, 27-34.

Garvie, E. I. (1978). Streptococcus raffinolactis Orla-Jensen and Hansen, a group $\mathrm{N}$ streptococcus found in raw milk. Int J Syst Bacteriol 28, 190-193.

Gregersen, R. H., Neubauer, C., Christensen, H., Bojesen, A. M., Hess, M. \& Bisgaard, M. (2009). Comparative studies on [Pasteurella] testudinis and $[P$.] testudinis-like bacteria and proposal of Chelonobacter oris gen. nov., sp. nov. as a new member of the family Pasteurellaceae. Int J Syst Evol Microbiol 59, 1583-1588.

Korczak, B., Christensen, H., Emler, S., Frey, J. \& Kuhnert, P. (2004). Phylogeny of the family Pasteurellaceae based on rpoB sequences. Int $J$ Syst Evol Microbiol 54, 1393-1399.

Kuhnert, P. \& Korczak, B. M. (2006). Prediction of whole-genome DNA-DNA similarity, determination of $\mathrm{G}+\mathrm{C}$ content and phylogenetic analysis within the family Pasteurellaceae by multilocus sequence analysis (MLSA). Microbiology 152, 2537-2548.

Kuhnert, P., Frey, J., Lang, N. P. \& Mayfield, L. (2002). Phylogenetic analysis of Prevotella nigrescens, Prevotella intermedia and Porphyromonas gingivalis clinical strains reveals a clear species clustering. Int $J$ Syst Evol Microbiol 52, 1391-1395.

Kuhnert, P., Korczak, B., Falsen, E., Straub, R., Hoops, A., Boerlin, P., Frey, J. \& Mutters, R. (2004). Nicoletella semolina gen. nov., sp. nov., a 
new member of Pasteurellaceae isolated from horses with airway disease. J Clin Microbiol 42, 5542-5548.

Kuhnert, P., Korczak, B. M., Christensen, H. \& Bisgaard, M. (2007). Emended description of Actinobacillus capsulatus Arseculeratne 1962, $38^{\mathrm{AL}}$. Int J Syst Evol Microbiol 57, 625-632.

Kuhnert, P., Scholten, E., Haefner, S., Mayor, D. \& Frey, J. (2010). Basfia succiniciproducens gen. nov., sp. nov., a new member of the family Pasteurellaceae isolated from bovine rumen. Int J Syst Evol Microbiol 60, 44-50.

Kuiken, T. \& Hartmann, M. G. (1991). Cetacean pathology: dissection techniques and tissue sampling. ECS Newsletter No. 17 (special issue).

Mayor, D., Korczak, B. M., Christensen, H., Bisgaard, M., Frey, J. \& Kuhnert, P. (2006). Distribution of RTX toxin genes in strains of [Actinobacillus] rossii and [Pasteurella] mairii. Vet Microbiol 116, 194-201.

Mutters, R., Ihm, P., Pohl, S., Frederiksen, W. \& Mannheim, W. (1985). Reclassification of the genus Pasteurella Trevisan 1887 on the basis of deoxyribonucleic acid homology, with proposals for the new species Pasteurella dagmatis, Pasteurella canis, Pasteurella stomatis, Pasteurella anatis and Pasteurella langaa. Int J Syst Bacteriol 35, 309-322.
Nørskov-Lauritsen, N. \& Kilian, M. (2006). Reclassification of Actinobacillus actinomycetemcomitans, Haemophilus aphrophilus, Haemophilus paraphrophilus and Haemophilus segnis as Aggregatibacter actinomycetemcomitans gen. nov., comb. nov., Aggregatibacter aphrophilus comb. nov. and Aggregatibacter segnis comb. nov., and emended description of Aggregatibacter aphrophilus to include V factor-dependent and V factor-independent isolates. Int J Syst Evol Microbiol 56, 2135-2146.

Nørskov-Lauritsen, N., Bruun, B. \& Kilian, M. (2005). Multilocus sequence phylogenetic study of the genus Haemophilus with description of Haemophilus pittmaniae sp. nov. Int J Syst Evol Microbiol 55, 449-456.

Osawa, R., Rainey, F., Fujisawa, T., Lang, E., Busse, H. J., Walsh, T. P. \& Stackebrandt, E. (1995). Lonepinella koalarum gen. nov., sp. nov., a new tannin-protein complex degrading bacterium. Syst Appl Microbiol 18, 368-373.

Patel, S. M., Mo, J. H., Walker, M. T., Adley, B. \& Noskin, G. A. (2004). Epidural abscess and osteomyelitis due to Actinobacillus actinomycetemcomitans. Diagn Microbiol Infect Dis 50, 283-285.

Stackebrandt, E. \& Ebers, J. (2006). Taxonomic parameters revisited: tarnished gold standards. Microbiol Today 33, 152-155. 